TecnoHumanismo. Revista Científica

Setiembre - Noviembre 2021

Volumen 1 / No.3

ISSN: $2710-2394$

pp.457-474

https://doi.org/10.53673/th.v1i12.85

https://tecnohumanismo.online

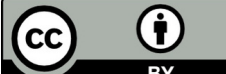

\title{
El reconocimiento constitucional del derecho de acceso a internet en la constitución política de 1993
}

The constitutional recognition of the right of internet access in the 1993 political constitution

O reconhecimento constitucional do direito de acesso à Internet na constituição política de 1993

ARTÍCULO GENERAL

\section{Luis Fernando Botto Cayo \\ Lbotto5@hotmail.com \\ https://orcid.org/0000-0003-0327-6742}

Ilustre Corte Superior de Justicia de Madre de Dios, Madre de Dios - Perú

Recibido 07 de Abril 2021 | Arbitrado y aceptado 19 de Junio 2021 | Publicado en 03 Setiembre 2021

\section{RESUMEN}

El propósito del presente trabajo fue analizar las percepciones sobre el reconocimiento constitucional del derecho de acceso a Internet y la eficacia del derecho al trabajo y la educación en la Constitución Política de 1993 en esta nueva normalidad que manejan los abogados de Lima Metropolitana, 2020. La investigación es socio jurídica cuantitativa y aplicada, el método es hipotético - deductivo, complementado con el método histórico jurídico. El diseño es no experimental y transeccional. El nivel es descriptivo y explicativo. La técnica de recolección de datos es la encuesta y el instrumento el cuestionario (Confiabilidad: 1,956). La población son los abogados de Lima Metropolitana. El muestreo es no probabilístico (380 abogados). Se concluye que la percepción sobre el reconocimiento constitucional del derecho de acceso a Internet y la eficacia del derecho al trabajo y la educación en la Constitución Política de 1993 es significativa y el grado de asociación o relación de las variables es 0.631 siendo sustancial, por ello, se confirma la hipótesis. Se recomienda que en segunda legislatura ordinaria se apruebe la Ley de reforma constitucional en un artículo independiente del derecho a la educación, y que se incluya la naturaleza de ser libre y abierto.

Palabras claves: Reforma Constitucional acceso al internet como derecho constitucional; derecho al trabajo, derecho a la educación.

\section{ABSTRACT}

The purpose of this work was to analyze the perceptions on the constitutional recognition of the right of access to the Internet and the effectiveness of the right to work and education in the Political Constitution of 1993 in this new normal that is handled by the lawyers of Metropolitan Lima, 2020. The The research is quantitative and applied socio-legal, the method is hypothetical - deductive, complemented by the historical - legal method. The design is nonexperimental and transectional. The level is descriptive and explanatory. The data collection technique is the survey and the instrument the questionnaire (Reliability: 1,956). The population is the lawyers of Metropolitan Lima. The sampling is non-probabilistic (380 lawyers). It is concluded that the perception of the constitutional recognition of the right of access to the Internet and the effectiveness of the right to work and education in the 1993 Political Constitution is significant and the degree of association or relationship of the variables is 0.631 , being substantial, therefore , the hypothesis is confirmed. It is recommended that in the second ordinary legislature the Constitutional Reform Law be approved in an independent article on the right to education, and that the nature of being free and open be included.

Keywords: Constitutional Reform; access to the internet as a constitutional right; right to work, right to education.

\section{RESUMO}

El propósito del presente trabajo fue analizar as percepciones sobre el reconocimiento constitucional del derecho de acceso a Internet y la eficacia del derecho al trabajo y la educación en la Constitución Política de 1993 en esta nueva normalidad que manejan los abogados de Lima Metropolitana, 2020. La investigación es socio jurídica cuantitativa y aplicada, el método es hipotético - deductivo, complementado con el método histórico jurídico. El diseño es no experimental y transeccional. El nivel es descriptivo y explicativo. La técnica de recolección de datos es la encuesta y el instrumento el cuestionario (Confiabilidad: 1,956). La población son los abogados de Lima Metropolitana. El muestreo es no probabilístico (380 abogados). Se concluye que la percepción sobre el reconocimiento constitucional del derecho de acceso a Internet y la eficacia del derecho al trabajo y la educación en la Constitución Política de 1993 es significativa y el grado de asociación o relación de las variables es 0.631 siendo sustancial, por ello, se confirma la hipótesis. Se recomienda que en segunda legislatura ordinaria se apruebe la Ley de reforma constitucional en un artículo independiente del derecho a la educación, y que se incluya la naturaleza de ser libre y abierto.

Palabras claves: Reforma Constitucional; acceso al internet como derecho constitucional; derecho al trabajo, derecho a la educación. 


\section{Introducción}

Ha transcurrido más de treinta años desde que el internet inició su difusión y no cabe duda que en estos últimos años ha generado un gran incremento debido a los desarrollos de las nuevas tecnologías que permiten acceder a todo tipo y contenido de información.

Ahora, el Internet no solo permite conectar a las personas entre sí, sino también a los ciudadanos con las diversas entidades públicas o privadas; y esta masificación se encuentra ya en todos los aspectos de la vida, sea económica, cultural, educativa. Esta problemática ha sido discutida en muchos foros organizados a nivel internacional, como en la Organización de las Naciones Unidas o en la Organización de los Estados Americanos, sobre el acceso a Internet como un derecho humano fundamental.

La emergencia internacional y nacional ocasionada por la epidemia del Coronavirus (COVID-19) en el Perú, el cual pone al descubierto la precariedad del sistema de salud y situó en agenda las deficiencias de los servicios públicos y la no satisfacción de los derechos constitucionales, como la educación o el trabajo. Así, en el campo de la educación millones de niños, adolescentes y jóvenes que cursan estudios tanto en la educación primaria, secundaria, universidades como institutos de educación superior vienen teniendo dificultades de acceso a la educación por no tener acceso a Internet.

Por ello, la Defensoría del Pueblo, en su labor de supervisión, advirtió que estudiantes de diversas provincias del Perú entre ellas las de Cajamarca, La Libertad, Ancash, Puno, Cuzco entre otras, no cuentan con Internet ni acceso de a la radio y televisión, así como escolares del Distrito de Ongón de la Provincia de Pataz, deben caminar por más de una hora para poder sintonizar la radio y la televisión muchas veces sin éxito debido a las condiciones climáticas para recibir sus clases a distancias exigidas por el Ministerio de Educación y los Institutos Superiores y las Universidades, exponiendo la mayoría de sus veces su salud, pues estas comunidades se encuentran en las zonas alto andinas en los que la presencia del frio es la constante.

Es cierto que el artículo 137.1, referido al Estado de emergencia, de la Constitución Política de 1993 restringe y limita el ejercicio de los derechos constitucionales relativos a la libertad y la seguridad personales, la inviolabilidad del 
domicilio, y la libertad de reunión. Sin embargo, el resto de los derechos se ven afectados en su ejercicio pues existe inequidad en la consecución de medios para contar con instrumentos digitales de acceso y comunicación.

En este orden de ideas, conforme lo señala la doctrina constitucional, el acceso al Internet es una condición necesaria para poder gozar los demás derechos constitucionales como el trabajo y a la educación. El Internet está constituido por un conjunto descentralizado de redes de comunicación interconectadas, el cual garantiza que las redes físicas no homogéneas que la integran constituyan una red lógica única de alcance mundial. Asimismo, que las personas deben contar con un hardware y un software y que exista una infraestructura de comunicación, sea a través de plataformas virtuales, cableados, fibras ópticas a cargo del Estado do de empresas con especial relevancia en el sistema educativo.

En este mismo orden de ideas, el Internet, es un medio tecnológico que debido a su gran difusión ha pasado a ser un espacio que garantiza el ejercicio de derechos constitucionales en circunstancias que antes no era posible. Queda claro que el Internet permite acortar las desigualdades entre las personas y sus diferencias y conseguir la inclusión social se necesita de su regulación.

Por estas consideraciones el Internet en la actualidad para las personas dejó de ser un privilegio para ser un derecho humano exigible y teniendo en cuenta lo desarrollado por los organismos internacionales que luchan por la defensa de los derechos humanos y su regulación como el acceso universal al Internet y también su reconocimiento constitucional en el derecho comparado, en el Perú con fecha 11 de marzo de 2021 el Congreso de la República, aprobó la modificación de la Constitución en primera votación con 104 votos. No obstante, nos encontramos ante una reforma constitucional, motivo por el cual se tiene que realizar una segunda votación en la siguiente legislatura para poder hacer efectiva dicha modificación.

La ley de Reforma constitucional del reconocimiento de acceso del internet aprobada en primera votación, en su dictamen de los Proyectos de Ley 3156/2018-CR, 3607/2018-CR, 5600/2020-CR y 5843/2020-CR, recogía las propuestas realizadas hasta el momento para el reconocimiento del derecho de acceso a Internet como un derecho constitucional, incorporaba en el artículo 14 el siguiente texto: 
El Estado garantiza el derecho de acceso a internet libre y abierto. Asimismo, promueve el desarrollo científico y tecnológico del país a través de la formación en las tecnologías de la información y comunicación, en especial para el sector educativo y en las zonas rurales del país.

Sin embargo, el texto final que fue aprobado fue el siguiente:

El Estado garantiza el derecho de acceso a internet. En las entidades, instituciones y espacios públicos su acceso es gratuito. Asimismo, promueve el desarrollo científico y tecnológico del país a través de la formación en las tecnologías de la información y comunicación, en especial para el sector educativo y en las zonas rurales del país.

Sin embargo, la reforma constitucional aprobada en primera legislatura no enmendó y mantuvo el derecho de acceso a Internet dentro del contenido de otro derecho como es el derecho a la educación, no cabe duda que esta regulación podría de traer problemas de interpretación constitucional pues, no se establecen contenidos para garantizar un efectivo ejercicio de este derecho, debió incorporarse en la norma constitucional el principio de neutralidad de red o proscribir posibles apagones de red. A nuestro juicio, erróneamente se retira de la propuesta del dictamen los principios de "libre" y "abierto" como contenidos de este derecho. El retiro de estos principios es preocupante, pues en el derecho de acceso a Internet si no se encuentra garantizada su apertura o su uso libre trae muchos problemas.

La aprobación de esta ley de reforma, es de vital importancia, pues la falta de conectividad limita el acceso a otros derechos constitucionales como a la educación y el trabajo. Ciertamente el derecho a acceso al Internet no contaba con un reconocimiento expreso en la Constitución Política del Perú de 1993. El Tribunal Constitucional del Perú, en la sentencia STC 02-2001-AI/TC (fj. 12), reconoció la importancia del Internet como derecho constitucional habilitador de otros derechos constitucionales. Estamos frente a un derecho que se constituye en "conditio sine quanon" para el disfrute y ejercicio de otros derechos constitucionales como el trabajo y el derecho a la educación.

Nuestro objetivo es analizar las percepciones sobre la ley de reforma constitucional del renocimiento en la Constitución del derecho de acceso a Internet y los derechos constitucionales del trabajo y educación en la Constitución Política del 
Perú de 1993. Y la pregunta central es: ¿Cómo son las percepciones sobre la ley de reforma constitucional del reconocimiento en la Constitución del derecho de acceso a Internet como condición sine quanon de los derechos constitucionales del trabajo y educación en la Constitución Política del Perú de 1993 que manejan los abogados que cumplen labor en Lima Metropolitana, en el año 2020?

\section{Material y Medios}

\subsection{Tipo y diseño de investigación}

El diseño de investigación es el no experimental, toda vez que no determina la existencia de variables independientes ni dependientes cumpliendo así los postulados de las pruebas de correlación. Para la recolección de los datos utilizamos el diseño transeccional, estos se recogieron al mismo tiempo, es decir fue monoetápico .

En nuestro estudio utilizamos el método hipotético - deductivo, por ello, se partió de lo general hacia lo particular, método que permite la falsación de hipótesis a través de la contrastación estadística inferencial de las mismas.

El método hipotético- deductivo se complementa con el método históricojurídico, para poder contar con documentos y así se reconstruyó la evolución de las instituciones jurídicas y sus principales reglas jurídicas para establecer el marco histórico-contextual, en el que se ha desarrollado la evolución de las instituciones del reconocimiento constitucional del acceso al Internet y los derechos constitucionales del trabajo y educación en la Constitución Política de 1993.

La unidad de análisis fueron los abogados que laboran en Lima Metropolitana. La población de estudio es de 43, 700 abogados que ejercen en Lima Metropolitana. El tamaño de la muestra es 380 abogados que ejercen en Lima Metropolitana. Para la recolección de datos utilizamos la encuesta de opinión aplicada a los abogados. El instrumento de recolección de la información fue el cuestionario estructurado. El cuestionario fue diseñado a partir de las dimensiones e indicadores que se desprenden de los objetivos de la investigación, las variables y las dimensiones e indicadores que fueron discriminados cuando se operacionalizaron las variables. 
La validez del cuestionario fue realizada mediante el juicio de experto, que en este caso fueron profesores de metodología que junto al docente del curso de seminario de tesis del programa maestría dieron fe de la misma.

\section{Marco teórico}

Según Melnick y Barraza (2002). El Internet nació para solucionar temas militares para el pentágono en 1960. En 1969 la Agencia ARPA del pentágono crea la red denominada ARPANET, su uso se amplió a cuatro universidades de Estados Unidos, University of;California Los Ángeles; Stanford University:]; California University Santa Bárbara y UTHA University.

El Internet ha cambiado a la civilización, en lo económico, político y social y logró ser un medio de comunicación abierto y universal, vinculado a la globalización de la sociedad. El Internet, como medio de comunicación masivo, permite el desarrollo de otros derechos como la libertad de pensamiento, conciencia y religión, también su manifestación y participación de las personas.

La sociedad de la información tiene su nacimiento en las nuevas tecnologías y nos va a permitir e almacenar y modificar, sin tener ningún límite de espacio, tiempo o volumen. No cabe duda que el desarrollo tecnológico es impresionante el cual impulsó el fenómeno del Internet.

Giraldo (2012) explica que el Internet es una de las herramientas de mayor trascendencia que se ha desarrollado en las últimas décadas, conjuntamente con la globalización han transformado el mundo y la forma como las personas interactúan local y globalmente.

Villena (2016) señala que Internet "ha transformado al mundo. De la mano con el fenómeno de la globalización, el desarrollo de la tecnología ha cambiado la forma en la que nos relacionamos como seres humanos y nuestra forma de organización. La celebración de contratos, la prestación de servicios, el cumplimiento de obligaciones, la relación entre ciudadano y Administración y el ejercicio de derechos son algunos de los aspectos de nuestra vida que se vieron modificados con el advenimiento de las tecnologías de la información y comunicación y, en especial, Internet”. 
Al respecto, Villena (2016), se pregunta ¿cómo se regula este fenómeno? O, una pregunta previa de necesaria respuesta, ¿se debe regular este fenómeno?, para ello recurre a las primeras soluciones de las que partió el movimiento libertario norteamericano para quienes la única posible regulación de Internet debe provenir de la autorregulación hecha por los internautas. Sin embargo, desde el surgimiento de Internet hasta ahora, sucedieron un gran número de cambios que hicieron que las posturas "ciberlibertarias" dejen de tener sustento.

Johnson y Post (1996), citados por Villena (2016), afirman que "al inicio sus creadores de Internet contribuyeron a construir una Red libre, pero desde los noventa esa situación ha cambiado un tanto con la aparición de programas favorecedores del control". Asimismo la presencia de actores privados y del Estado sacó a relucir que, efectivamente, el ciberespacio no era una realidad desconectada del "mundo real", sino más bien es la plasmación de relaciones humanas preexistentes a través de Internet. Valle, (2016).

En el año 1991, la Red Científica Peruana trajo al Perú esta tecnología y desde esa fecha la conectividad ha todo en aumento llegando a la mayoría de los lugares de nuestro país. La Red Científica Peruana es una asociación que tiene 'por finalidad la promoción y desarrollo de internet en el Perú y cada día fortalece a las personas e instituciones a través del uso de las tecnologías de información, promoviendo así, el desarrollo de la identidad, la libertad y la competitividad,

Rivas (2020), en su investigación Derecho al Internet desde la noción de las necesidades humanas, llega a la conclusión, que el derecho al Internet no deja de ser una necesidad básica humana y que es necesario su reconocimiento constitucional con la finalidad de garantizar no sólo el goce y disfrute del derecho al Internet en sí mismo, sino fundamentalmente para permitir el disfrute de otros derechos fundamentales que requieren de éste para su satisfacción, como el derecho al trabajo y a la educación. En el actual contexto en que vivimos de la pandemia del coronavirus, la importancia se manifiesta en el sentido que la ausencia del Internet genera una grave limitación para la satisfacción de necesidades humanas básicas. Asimismo, se incrementa las brechas de la desigualdad.

Arbildo (2020) en su trabajo Derecho de acceso a Internet: ¿debe reconocerse como derecho fundamental? tiene como principal objetivo analizar el acceso a Internet 
como un como derecho fundamental. Utilizando una metodología dogmática, en base a la técnica documental de estudio llega a la conclusión de que el derecho de acceso a Internet garantiza la conectividad y el acceso de manera universal, y que este derecho es habilitador, porque es condición sine qua non para el ejercicio efectivo de otros derechos, entre los cuales podemos mencionar el derecho al trabajo y educación.

Landa (2018) en su investigación Derecho fundamental al Internet: contenido esencial, tiene como objetivo demostrar que la interconectividad va en aumento, gracias a la utilización de las nuevas tecnologías de la comunicación, como el internet. El internet ha modificado los derechos constitucionales, como la libertad de expresión y el derecho a la intimidad. El internet permite construir la nueva identidad de los derechos constitucionales. La metodología de estudio es hermenéutica y la técnica de análisis es la documental.

Mateus (2018), en su trabajo de investigación Internet como derecho constitucional en el Perú: sentido y desafío, tiene como objetivo analizar las razones por las cuales el acceso a Internet debe reconocerse como derecho constitucional, utilizando el método dogmático llega a las siguientes conclusiones: el Internet no debe privarnos de ver los enormes desafíos para el ejercicio para este derecho. En tiempos de una creciente información, con imágenes muchas de ellas manipuladas y noticias falsas, la mayoría de usuarios no cuentan con capacidades suficientes para interactuar con contenidos y medios de forma crítica.

Peláez (2013), en su investigación denominada La protección efectiva de las imágenes en el internet desde la aplicación de la normatividad relativa al derecho de autor, tiene como objetivo abordar los problemas que afronta la protección de las imágenes en la era dgital, en virtud a las complejidades y retos que el Internet planteó para el Derecho de Autor, la metodología empleada es dogmática y la técnica de análisis utilizada es la documental. Llega a la conclusión de que el uso de este avance tecnológico dificulta que el autor de una obra protegida, pueda controlar su explotación.

La ley de Reforma constitucional del reconocimiento de acceso del internet

La ley de Reforma constitucional del reconocimiento de acceso del internet aprobada en primera votación por el Congreso de la República, el 11 de marzo de 2021 en su dictamen de los Proyectos de Ley 3156/2018-CR, 3607/2018-CR, 5600/2020-CR 
y 5843/2020-CR, recogió las propuestas realizadas hasta el momento para el reconocimiento del derecho de acceso a Internet como un derecho constitucional, incorporaba en el artículo 14.

\section{Resultados}

\section{Descripción general}

Tabla 1: Descripción general de los abogados encuestados.

\begin{tabular}{|c|c|c|c|c|c|c|c|c|c|c|}
\hline \multicolumn{3}{|l|}{ Edad } & \multicolumn{4}{|l|}{ Sexo } & \multicolumn{4}{|c|}{ Nivel de estudio } \\
\hline & \multirow[t]{2}{*}{ Frec } & \multirow[t]{2}{*}{$\%$} & \multicolumn{2}{|l|}{ M } & \multicolumn{2}{|l|}{$\mathrm{F}$} & \multicolumn{2}{|c|}{$\begin{array}{l}\text { Sin } \\
\text { Posgrado }\end{array}$} & \multicolumn{2}{|c|}{$\begin{array}{l}\text { Con } \\
\text { Posgrado }\end{array}$} \\
\hline & & & Frec & $\%$ & Frec & $\%$ & Frec & $\%$ & Frec & $\%$ \\
\hline $\begin{array}{l}25 \mathrm{a} \\
30 \\
\text { años }\end{array}$ & 38 & 10 & \multirow{4}{*}{115} & \multirow{4}{*}{$55 \%$} & \multirow{4}{*}{94} & \multirow{4}{*}{$45 \%$} & \multirow{4}{*}{63} & $20 \%$ & \multirow{4}{*}{146} & $80 \%$ \\
\hline $\begin{array}{l}30 \mathrm{a} \\
40 \\
\text { años }\end{array}$ & 57 & 15 & & & & & & $20 \%$ & & $80 \%$ \\
\hline $\begin{array}{l}40 \\
\text { años a } \\
50 \\
\text { años }\end{array}$ & 209 & 55 & & & & & & $30 \%$ & & $70 \%$ \\
\hline $\begin{array}{l}\text { Más de } \\
50 \\
\text { años }\end{array}$ & 76 & 20 & & & & & & $30 \%$ & & $70 \%$ \\
\hline Total & 380 & 100 & & & & & & & & \\
\hline
\end{tabular}

La edad de los encuestados se presenta en la tabla 4. Se observa que el mayor porcentaje de encuestados se ubica en el intervalo entre 40 y 50 años (55\%), seguido por el grupo etario de más de 50 años (30\%). Los grupos con menor porcentaje son el de 20 a 30 años (10\%), y el de 30 a 40 años (15\%). Los intervalos con mayor frecuencia indican que la muestra seleccionada en un $80 \%$ podría reunir experticia en temas legales asumiéndose una estimación a partir de la edad.

Se observó una distribución porcentual no muy disímil entre los encuestados del sexo masculino (55\%) y las féminas (45\%), garantizando esto equidad de género en las respuestas (ver tabla 4). A nivel de estudios prevalecieron los abogados con posgrado (70\%) por sobre los encuestados que no tenían un postgrado (30\%). El porcentaje de estudios posteriores a la obtención del título profesional es indicador del grado de formación profesional de los encuestados es un buen indicador (ver tabla 1). 
Percepción sobre la Ley de Reforma del reconocimiento constitucional del derecho de acceso a Internet

\section{Ley de Reforma del reconocimiento constitucional de acceso a Internet}

Tabla 2: Resultados de los ítems que confirman la dimensión ley de la Reforma del reconocimiento constitucional de acceso a Internet y órganos competentes

\begin{tabular}{|l|l|l|l|l|l|}
\hline ÍTEM & $\begin{array}{l}\text { Totalmente } \\
\text { en } \\
\text { desacuerdo }\end{array}$ & $\begin{array}{l}\text { En } \\
\text { desacuerdo }\end{array}$ & Indeciso & $\begin{array}{l}\text { En } \\
\text { acuerdo }\end{array}$ & $\begin{array}{l}\text { Totalmente } \\
\text { en acuerdo }\end{array}$ \\
\hline $\begin{array}{l}\text { 1. Congreso de la } \\
\text { República }\end{array}$ & 0.00 & 0.00 & 0.00 & $3.70 \%$ & $96.30 \%$ \\
\hline 2. Pueblo & 0.00 & 0.00 & 0.00 & $9.50 \%$ & $90.50 \%$ \\
\hline 3. Tribunal Constitucional & 0.00 & 0.00 & 0.00 & $\begin{array}{l}26.10 \\
\%\end{array}$ & $73.9 \%$ \\
\hline
\end{tabular}

El examen sobre la dimensión Ley de Reforma del reconocimiento constitucional de acceso a Internet indica una prevalencia del Congreso de la República reflejada en el ítem 1, que agrupa un $100 \%$ de las respuestas en las categorías en acuerdo $(3,70 \%)$ y totalmente en acuerdo $(96.30 \%)$.

El Pueblo como reformador de la Constitución, interrogada con el ítem 2, resultó ser la de segunda agrupando en un 100\% de las respuestas en las categorías en acuerdo $(9,50 \%)$ y totalmente en acuerdo $(90,50 \%)$.

El Tribunal Constitucional también logró acuerdo (26,10 \%) y totalmente en acuerdo (73,9\%). Los encuestados entendieron que el competente para evaluar la constitucionalidad de las leyes de reforma constitucional es el Tribunal Constitucional.

El análisis a partir de los datos observados indica que el Congreso de la República, el Pueblo y el Tribunal Constitucional se perciben como presentes en el marco de la Reforma Constitucional. La diferencia entre sus valoraciones expresada en términos de porcentajes refleja un predominio del Congreso de la República luego le sigue el Pueblo. 


\section{Los límites de la Reforma Constitucional}

Tabla 3: Resultados de los ítems que conforman la dimensión de los límites de la Reforma Constitucional

\begin{tabular}{|l|l|l|l|l|l|}
\hline ÍTEM / Indicador & $\begin{array}{l}\text { Totalmente } \\
\text { en } \\
\text { desacuerdo }\end{array}$ & $\begin{array}{l}\text { En } \\
\text { desacuerdo }\end{array}$ & Indeciso & $\begin{array}{l}\text { En } \\
\text { acuerdo }\end{array}$ & $\begin{array}{l}\text { Totalmente } \\
\text { en acuerdo }\end{array}$ \\
\hline 1. Formales & 0 & 0 & 0 & 33.7 & 66,3 \\
\hline $\begin{array}{l}\text { 2. Materiales } \\
\text { expresos }\end{array}$ & 0 & 0 & 5,3 & 33.5 & 61,2 \\
\hline $\begin{array}{l}\text { 3. Materiales } \\
\text { implícitos }\end{array}$ & 0 & 0 & 9.8 & 32.8 & 57.4 \\
\hline
\end{tabular}

La exploración sobre la dimensión de los límites de la Reforma Constitucional indica que tres límites son elementos estructurales de la Reforma Constitucional. Los límites formales se refieren a que el Congreso de la República y el pueblo pueden realizar la reforma a través del procedimiento a seguir para ello y si es que se debe plantear un referéndum que confirme o no la reforma. (ver tabla 3 ).

Los límites que tiene el Congreso de la República no se limitan a lo formal referido a los procedimientos establecidos ante la autoridad, también incluye límites materiales. El competente para evaluar la constitucionalidad de las leyes de reforma constitucional es el Tribunal Constitucional.

Los límites formales obtuvieron un acuerdo de 33,7 \% y un total acuerdo de 66,3\%. Para los límites materiales expresos se observó un acuerdo de 33,5 \% y un total acuerdo de 61,2\%. Sin embargo, aparece reflejado un 5,3\% de indecisión. La percepción sobre los limites materiales implícitos muestra un acuerdo de 32,8 \% y un total acuerdo de $57,4 \%$. 
Las generaciones de los derechos humanos

Tabla 4: Resultados de los ítems que conforman la dimensión generación de los derechos humanos

\begin{tabular}{|l|l|l|l|l|l|}
\hline ÍTEM / Indicador & $\begin{array}{l}\text { Totalme } \\
\text { nte en } \\
\text { desacuer } \\
\text { do }\end{array}$ & $\begin{array}{l}\text { En } \\
\text { desacuer } \\
\text { do }\end{array}$ & $\begin{array}{l}\text { Indeci } \\
\text { so }\end{array}$ & $\begin{array}{l}\text { De } \\
\text { acuer } \\
\text { do }\end{array}$ & $\begin{array}{l}\text { Totalme } \\
\text { nte en } \\
\text { acuerdo }\end{array}$ \\
\hline $\begin{array}{l}\text { 1. Derechos humanos de primera } \\
\text { generación }\end{array}$ & 0 & 0 & 4,2 & 28,1 & 67.7 \\
\hline $\begin{array}{l}\text { 2. Derechos humanos de segunda } \\
\text { generación }\end{array}$ & 0 & 0 & 0 & 31.4 & 68.6 \\
\hline $\begin{array}{l}\text { 3. Derechos humanos de tercera } \\
\text { generación }\end{array}$ & 0 & 0 & 9.8 & 28.5 & 61.7 \\
\hline $\begin{array}{l}\text { 4. Derechos humanos de cuarta } \\
\text { generación }\end{array}$ & 0 & 0 & 12.2 & 30.7 & 57.1 \\
\hline
\end{tabular}

La tercera dimensión de la primera variable examina las generaciones de los derechos humanos (ver tabla 4). Los derechos humanos de primera generación, presenta un acuerdo de $28,1 \%$ y un total acuerdo de $67.7 \%$, estando estos acompañados de un 4,2\% de indecisión. Los derechos humanos de segunda generación, exhibe un total acuerdo del 68,6\%, y un acuerdo de 31,4\%. Los derechos humanos de tercera generación presentan un acuerdo de $28,5 \%$ y un total acuerdo de $61.7 \%$, con un $9.8 \%$ de indecisión. Los derechos humanos de cuarta generación presentan un acuerdo de 30,7\% y un total acuerdo de $57,1 \%$, con un $12,2 \%$ de indecisión.

\section{El acceso a Internet como derecho constitucional}

Tabla 5: Resultados de los ítems que conforman la dimensión del acceso a

\section{Internet como derecho constitucional}

\begin{tabular}{|l|l|l|l|l|l|}
\hline ÍTEM / Indicador & $\begin{array}{l}\text { Totalmente } \\
\text { en } \\
\text { desacuerdo }\end{array}$ & $\begin{array}{l}\text { En } \\
\text { desacuerdo }\end{array}$ & e & $\begin{array}{l}\text { De } \\
\text { acuerdo }\end{array}$ & $\begin{array}{l}\text { Totalmente } \\
\text { en acuerdo }\end{array}$ \\
\hline 1. Derecho constitucional social & 0 & 0 & 0 & 14.9 & 85.1 \\
\hline $\begin{array}{l}\text { 2. El derecho de acceso al } \\
\text { Internet es un servicio universal } \\
\text { que el Estado debe garantizar a } \\
\text { las personas. }\end{array}$ & 0 & 0 & 0 & 37.4 & 62.6 \\
\hline $\begin{array}{l}\text { 3. Tiene contenido esencial del } \\
\text { acceso al internet como derecho }\end{array}$ & 0 & 0 & & 38.5 & 61.5 \\
\hline
\end{tabular}


En cuanto a la dimensión del acceso a Internet como derecho constitucional se examinó la percepción de tres de ellos (ver tabla 5). Solo tres indicadores tuvieron una valoración totalmente positiva. El primero corresponde al acceso al internet como derecho social que muestra un acuerdo de $14,9 \%$ y un total de acuerdo de $85.1 \%$. El otro ítem se refiere al derecho de acceso al Internet como un servicio universal que el Estado debe garantizar a las personas estan de acuerdo los encuestados en un 37,4\% y total de acuerdo de $62,6 \%$. El tercer ítem se trata del contenido esencial del acceso al internet como derecho, los encuestados respondieron estar de acuerdo 38,5\% y total de acuerdo $61,5 \%$.

Percepción sobre la eficacia de los derechos constitucionales del trabajo y educación en la Constitución Política del Perú de 1993

Naturaleza jurídica del derecho al trabajo

Tabla 6: Resultados de los ítems que conforman la dimensión naturaleza jurídica del derecho al trabajo

\begin{tabular}{|l|l|l|l|l|l|}
\hline ÍTEM / Indicador & $\begin{array}{l}\text { Totalmente } \\
\text { en } \\
\text { desacuerdo }\end{array}$ & $\begin{array}{l}\text { En } \\
\text { desacuerdo }\end{array}$ & Indeciso & $\begin{array}{l}\text { En } \\
\text { acuerdo }\end{array}$ & $\begin{array}{l}\text { Totalmente } \\
\text { en acuerdo }\end{array}$ \\
\hline 1. Derecho constitucional & 0 & 0 & 0 & 2.3 & 97.7 \\
\hline 2. Prestación personal & 0 & 0 & 0 & 10.3 & 89.7 \\
\hline 3. Subordinación & 0 & 0 & 0 & 22.9 & 77.1 \\
\hline 4. Remuneración & 0 & 0 & 0 & 10.1 & 88.9 \\
\hline
\end{tabular}

La dimensión naturaleza jurídica del derecho al trabajo está conformada por cuatro ítems que abordan las cuatro características sobre las que se fundamenta el derecho del trabajo (ver tabla 6). Se observa que todas las características tuvieron una valoración mayoritariamente positiva. La característica derecho constitucional presenta el promedio más alto, que muestra un acuerdo de 2,3\% y un total de acuerdo de 97,7\%. La segunda característica de la naturaleza jurídica del trabajo estos porcentajes de acuerdo del $10.3 \%$ y de total de acuerdo de $89,7 \%$. La tercera característica referida a la subordinación muestra un $22.9 \%$ de acuerdo y un $\quad 77.1 \%$ total acuerdo. La cuarta característica denominada remuneración muestra un acuerdo del $10.1 \%$ y un $88.9 \%$ en total acuerdo. 
Modalidades del Derecho al trabajo producido por los cambios tecnológicos

Tabla 7: Resultados de los ítems que conforman la dimensión modalidades del Derecho al trabajo producido por los cambios tecnológicos

\begin{tabular}{|l|l|l|l|l|l|}
\hline ÍTEM / Indicador & $\begin{array}{l}\text { Totalmente } \\
\text { en } \\
\text { desacuerdo }\end{array}$ & $\begin{array}{l}\text { En } \\
\text { desacuerdo }\end{array}$ & Indeciso & $\begin{array}{l}\text { En } \\
\text { acuerdo }\end{array}$ & $\begin{array}{l}\text { Totalmente } \\
\text { en acuerdo }\end{array}$ \\
\hline 1. Trabajo remoto & 0 & 0 & 0 & 3.2 & 96.8 \\
\hline 2. Teletrabajo & 0 & 0 & 0 & 1.4 & 98.6 \\
\hline $\begin{array}{l}\text { 3. Trabajo a } \\
\text { domicilio }\end{array}$ & 0 & 0 & 0 & 6.1 & 93.9 \\
\hline
\end{tabular}

El análisis de la dimensión modalidades del Derecho al trabajo producido por los cambios tecnológicos contempló la pregunta sobre las diversas modalidades y contemplo el trabajo remoto en el que están de acuerdo el 3,2\% y en total acuerdo $96.8 \%$. El segundo ítem denominado teletrabajo estuvieron de acuerdo el 1.4\% y en total acuerdo un $98.6 \%$. El tercer ítem referente al trabajo a domicilio, respondieron estar de acuerdo un $6.1 \%$ y en total acuerdo un 93,9\%.(ver tabla 7 ). 
Naturaleza jurídica del derecho a la educación

Tabla 8: Resultados de los ítems que conforman la dimensión naturaleza jurídica del derecho a la educación

\begin{tabular}{|l|l|l|l|l|l|}
\hline ÍTEM / Indicador & $\begin{array}{l}\text { Totalmente } \\
\text { en } \\
\text { desacuerdo }\end{array}$ & $\begin{array}{l}\text { En } \\
\text { desacuerdo }\end{array}$ & Indeciso & $\begin{array}{l}\text { En } \\
\text { acuerdo }\end{array}$ & $\begin{array}{l}\text { Totalmente } \\
\text { en acuerdo }\end{array}$ \\
\hline 1. Derecho constitucional & 0 & 0 & 0 & 2.3 & 97.7 \\
\hline 2. Servicio 'Publico & 0 & 0 & 0 & 1.9 & 98.1 \\
\hline 3. Bienes constitucionales & 0 & 0 & 0 & 1.3 & 98.7 \\
\hline $\begin{array}{l}\text { 4. El derecho a la educación } \\
\text { y el libre desarrollo de la } \\
\text { persona humana }\end{array}$ & 0 & 0 & 0 & 2.1 & 97.9 \\
\hline $\begin{array}{l}\text { 5. La disponibilidad del } \\
\text { derecho a la educación }\end{array}$ & 0 & 0 & 0 & 1.1 & 98,9 \\
\hline
\end{tabular}

La dimensión naturaleza jurídica del derecho a la educación la constituyen cinco ítems (ver tabla 8). El primero precisa que es un derecho constitucional en el cual un $2,3 \%$ están de acuerdo y un $97,7 \%$ en total acuerdo. El segundo ítem trata de la educación como servicio público respondieron estar de acuerdo un $1.9 \%$ y en total acuerdo $98,1 \%$, ciertamente asociación a la educación como un derecho y un servicio. El tercer ítem trata de la educación en relación con los bienes constitucionales, en el que respondieron estar de acuerdo un 1,3\% y en total acuerdo un $98.7 \%$. El cuarto ítem denominado el derecho a la educación y el libre desarrollo de la persona humana respondieron los encuestados estar de acuerdo 2,1 y en total acuerdo un 97.9\%. El quinto ítem denominado la disponibilidad del derecho a la educación respondieron estar de acuerdo un $1,1 \%$ y en total acuerdo un $98,9 \%$.

\section{Conclusiones}

También se puede concluir a partir de las opiniones de los encuestados que manifestaron estar totalmente de acuerdo con que la naturaleza jurídica de la educación es un derecho constitucional, es un servicio, está en función de bienes constitucionales, es un derecho de libre desarrollo y disponibilidad. Asimismo, manifestaron los encuestados estar totalmente de acuerdo con las modalidades de educación a distancia producto de los cambios tecnológicos. 
La relación estadística entre las percepciones sobre la ley de reforma del reconocimiento constitucional en la Constitución del derecho de acceso a Internet y la eficacia de los derechos constitucionales del trabajo y educación en la Constitución Política del Perú de 1993 arroja una relación significativa a nivel de variables. Asimismo, a nivel de dimensiones se concluye que los factores que permiten la eficacia de los derechos al trabajo y a la educación están relacionadas significativamente con las cuatro dimensiones de la variable percepción sobre la ley de reforma constitucional que permiten el reconocimiento constitucional de acceso al Internet. Esto indica que a medida que se incrementa la percepción de aceptación de estas dimensiones también aumenta la percepción positiva sobre la eficacia de los derechos al trabajo y la educación.

Se concluye que la hipótesis general del trabajo fue demostrada pues los datos estadísticos confirman que el reconocimiento en la Constitución del derecho de acceso a Internet es condición sine quanon para la eficacia de los derechos constitucionales del trabajo y educación en la Constitución Política del Perú de 1993.

\section{RECOMENDACIONES}

1. Promover que el Congreso de la República apruebe en segunda legislatura ordinaria la Ley de Reforma Constitucional de reconocimiento constitucional de acceso al Internet, y que sea regulada de manera independiente pues en la primera legislatura se aprobó su reconocimiento constitucional dentro del artículo 14 referido al derecho a la educación el cual traería problemas de interpretación. También debe especificarse que el Estado debe garantizar el derecho de acceso a internet libre y abierto.

2. Difundir a nivel de las Facultades de Derecho y Ciencia Política y en los Colegios de Abogados los resultados de la investigación de tal forma que sea del dominio público los resultados y se estimule una discusión jurídica sobre el tema.

3. 3. Replicar la investigación en otras ciudades para contar con mayor información que pueda respaldar que la ley de Reforma Constitucional del reconocimiento de acceso del derecho a Internet. 


\section{Referencias bibliográficas}

Arbildo, N. (2020). "Derecho de acceso a Internet: ¿debe reconocerse como derecho fundamental?". Pasión por el derecho. https://lpderecho.pe/acceso-Internetderecho-fundamental.

Giraldo, C. (2012). La influencia del consumo de Internet en la comunicación entre adolescentes y padres en zonas rurales. Tesis para optar el Título de Licenciada en Comunicación para el Desarrollo. Facultad de Ciencias Y Artes de la Comunicación. Pontificia Universidad Católica del Perú.

Landa, c. (2018) en su investigación Derecho fundamental al Internet: contenido esencial. Pensar Revista de Ciencias Jurídicas. V. 23. №. 4. file://C:/Users/toshiba/Downloads/8447-31968-1-PB.pdf

Mateus, J.C. (2020). "Internet como derecho constitucional en el Perú: sentido y desafío". https://bit.ly/mpyov.

Melnick, S. y Barraza, J. (2002). “e-business, sí o sí”. Centro de Estudio de la Economía Digital 2002, de la Cámara de Comercio de Santiago.

Peláez, M. (2013), La protección efectiva de las imágenes en el internet desde la aplicación de la normatividad relativa al derecho de autor. Tesis para optar el grado de Magíster en Propiedad Intelectual y Competencia. Escuela de Graduados de la Pontificia Universidad Católica del Perú. http://tesis.pucp.edu.pe/repositorio/bitstream/handle/20.500.12404/4944/PELAEZ CHAVEZ_MARIA_PROTECCION_IMAGENES.pdf?sequence $=1 \&$

Rivas, (2020). "Derecho al Internet desde la noción de las necesidades humanas".

Enfoque derecho.https://www.enfoquederecho.com/2020/04/23/derecho-alInternet-desde-la-nocion-de-las-necesidades-humanas-basicas.

Villena, D. (2016). "La trascendencia constitucional de la neutralidad de red". Themis $\mathrm{N}^{\circ}$ 70. Pontificia Universidad Católica del Perú.

Johnson, D. y Post, D. (1996) "Law and Borders - The Rise of Law in Cyberspace". Stanford Law. Review.N. 48. 